\title{
RELAÇÕES ENTRE FALA E ESCRITA NA ESCOLA: ANÁLISE DA PRÁTICA DE UMA PROFESSORA DO ENSINO FUNDAMENTAL ${ }^{1}$
}

\author{
THE RELATIONSHIPS BETWEEN ORAL AND WRITTEN LANGUAGE AT SCHOOL: \\ THE ANALYSIS OF AN ELEMENTARY SCHOOL (SECOND SEGMENT) TEACHER'S \\ PRACTICE
}

\author{
Laís Maria Álvares Rosal Botler \\ Mestre em Educação pela Universidade Federal de Pernambuco \\ laisrosal@yahoo.com.br \\ Lívia Suassuna \\ Docente da Universidade Federal de Pernambuco \\ livia.suassuna@ufpe.br
}

RESUMO: Objetivamos, no presente artigo, descrever e analisar o modo como uma professora do ensino fundamental de uma escola pública do Estado de Pernambuco aborda a oralidade e suas relações com a escrita em sua sala de aula, pondo em relevo inovações que consideramos importantes para o contexto geral do ensino de português como língua materna. Baseamo-nos em apontamentos teóricos, dentre outros, de Marcuschi (2010); Fávero, Andrade e Aquino (1999; 2011); Antunes (2003); e Braun (2003). No intuito de atingir esses objetivos, desenvolvemos uma pesquisa qualitativa do tipo etnográfico, realizando observações de aulas de uma professora do Ensino Fundamental, com foco na maneira como ela aborda as relações entre a fala e a escrita em suas aulas. A análise dos dados indicou que: (a) a modalidade oral da língua foi tomada como objeto autônomo de ensino e suas relações de semelhança e diferença com a modalidade escrita foram discutidas com profundidade; (b) a formação inicial e continuada a que a professora teve acesso influenciou positivamente o seu trabalho; (c) as aulas em que a modalidade oral foi trabalhada e abordada em relação à escrita se mostraram como ricas oportunidades para que os alunos se colocassem por meio de suas falas e, assim, se constituíssem como construtores dos próprios discursos.

PALAVRAS-CHAVE: ensino de língua portuguesa; ensino de oralidade; relações entre fala e escrita.

ABSTRACT: In this paper, we aimed to describe and to analyze the way a public school teacher from the second segment of elementary school (6th to 9th grades) approaches the oral language and its relations with the written language on her classrooms, trying to highlight the innovations that we noticed on her practice for the general Portuguese teaching context. We based on the theoretical appointments of Marcuschi (2010); Favero, Andrade e Aquino (1999; 2011), Antunes (2003), Braun (2003), and others. In order to reach this objective, we developed a qualitative research with ethnographic characteristics and conducted classe's observation, focusing on how the teacher worked the relations between spoken and written language. We noticed that the oral language is taken as object of study and its relations with written language are deeply discussed with her students. It was clear on her practice in the classroom the influence of her

\footnotetext{
${ }^{1}$ Este artigo é um recorte da dissertação de mestrado defendida junto ao Programa de Pós-graduação em Educação da UFPE e intitulada: "Gêneros orais e ensino de língua portuguesa: concepções e práticas" (BOTLER, 2013).
} 
beginning and continuous academic formation. Besides that, the classes in which the oral language was approached were great opportunities to the students speak, and then, constitute themselves as discuss constructors.

KEYWORDS: teaching of Portuguese language; teaching of oral language; spoken and written language relations.

\section{INTRODUÇÃO}

As mudanças ocorridas após a década de 1980 na maneira de se conceber a linguagem, o sujeito e o texto levaram a novas maneiras de se perceber também as relações entre oralidade e letramento. Partindo da visão de língua e texto como um conjunto de práticas sociais, Marcuschi (2010) defende que não é possível realizar investigações sobre a oralidade e o letramento sem articulá-los a seus papéis na civilização contemporânea. Da mesma maneira, não é possível estabelecer semelhanças e diferenças entre os contrapontos formais dessas práticas, ou seja, a fala e a escrita, sem associá-las a seus usos cotidianos.

O autor aponta, como um fator relevante para compreender a maneira como são tratadas as relações entre fala e escrita, o status que a escrita ganhou ao longo do tempo, por se tornar uma tecnologia indispensável no cotidiano e por ser uma forma de registro das atividades sociais de letramento. Por outro lado, ressalta que o homem é principalmente caracterizado pela fala, e não pela escrita. Nenhum desses fatores, no entanto, pressupõe que uma das modalidades é superior à outra, ou que a escrita é uma mera representação da fala. Ambas são, na visão do autor, práticas de uma mesma língua, com características diferentes, mas que não supõem dois sistemas distintos.

Apesar disso, no âmbito escolar, durante muito tempo a modalidade oral da língua foi relegada a segundo plano enquanto objeto de ensino, ou até mesmo completamente ignorada. Uma das principais justificativas para esse fato é a crença de que, ao chegar à escola, o aluno já sabe falar. Outra razão é a associação da fala à falta de planejamento, à espontaneidade e, principalmente, a erros linguísticos (DOLZ et al., 2004).

Tendo essas questões em vista, objetivamos, no presente artigo, descrever e analisar o modo como uma professora do ensino fundamental de uma escola pública do Estado de Pernambuco aborda a oralidade e suas relações com a escrita em sua sala de aula, pondo em relevo inovações que consideramos importantes para o contexto geral do ensino de português como língua materna.

Inicialmente traremos, no presente artigo, os autores e posicionamentos em que nos baseamos no que concerne às concepções de oralidade e às relações entre fala e escrita $\mathrm{e}$ sua abordagem na escola. Em seguida, explicaremos a metodologia adotada na pesquisa e, posteriormente, realizaremos a descrição e a análise das aulas observadas. Por fím, apresentaremos as considerações finais de nosso trabalho.

\section{CONCEPÇÕES DE ORALIDADE E RELAÇÕES FALA/ESCRITA}

Ao tratar das relações entre fala e escrita, Marcuschi (2010) afirma que é necessário ter consciência da primazia cronológica da oralidade e dos valores sociais que estão 
implícitos na valorização da escrita, principalmente pelo fato de esta se constituir como uma tecnologia aprendida em contextos formais, o que historicamente lhe conferiu maior valor. Para o autor, é importante indagar se "as relações entre fala e escrita são uniformes, constantes e universais, ou se elas são diversificadas na história, no espaço e nas línguas" (MARCUSCHI, 2010, p. 26). A partir dessa indagação, ele destaca diferentes maneiras de observar essas relações e, ao mesmo tempo, busca sugerir a maneira que ele acredita ser a mais adequada para tratar essas duas modalidades da língua.

A primeira dessas maneiras é a que se apoia numa dicotomia, ou seja, abordam-se a fala e a escrita como sendo opostas. Isso se dá porque os autores que trabalham nessa perspectiva se centram no código linguístico, sem se preocupar com os usos da língua ou com a produção textual. Foi essa perspectiva, de acordo com Marcuschi (2010), que originou o prescritivismo de uma única norma linguística. Vê-se aqui a clara influência da concepção de linguagem como expressão do pensamento, a qual não contempla os usos e as situações de produção dos discursos. É dessa perspectiva que derivou a divisão entre língua falada e língua escrita, tendo cada uma das modalidades propriedades específicas e exclusivas, como se pode ver no quadro abaixo:

Quadro 1: Dicotomias estritas

\begin{tabular}{|c|c|c|}
\hline Fala & Versus & Escrita \\
\hline Contextualizada & & Descontextualizada \\
\hline Dependente & & Autônoma \\
\hline Implícita & & Explícita \\
\hline Redundante & & Condensada \\
\hline Não Planejada & & Planejada \\
\hline Imprecisa & & Precisa \\
\hline Não Normatizada & & Normatizada \\
\hline Fragmentária & & Completa \\
\hline
\end{tabular}

Fonte: Marcuschi (2010, p. 27)

Marcuschi considera que, embora essa visão dicotômica dê "[...] bons resultados na descrição estritamente empírica..." (MARCUSCHI, 2010, p. 28), ela é totalmente insensível aos fenômenos dialógicos e discursivos. Além disso, ela tem o problema de conceber a fala como caos, espontaneísmo e lócus do erro, em oposição à escrita, que seria o lugar "da norma e do bom uso da língua" (MARCUSCHI, 2010).

A segunda tendência, de acordo com o autor, é a culturalista, que, apesar de contemplar as práticas de linguagem, é pouco adequada para a análise específica de certos fenômenos da língua por ser mais desenvolvida em outras áreas do conhecimento, como antropologia e psicologia. Para alguns teóricos que se filiam a essa perspectiva, a escrita representa um avanço cognitivo dos indivíduos e sua introdução em algumas culturas provocou grandes alterações na vida humana. Marcuschi destaca o valor dado à escrita a partir dessa visão, ressaltando, todavia, que esse valor não é intrínseco, mas sim relacionado à sociedade em que a escrita se desenvolve e à importância dada à escrita por essa sociedade. O autor aponta, então, alguns problemas encontrados na visão dos adeptos dessa tese, como o etnocentrismo, a supervalorização da escrita e o tratamento globalizante em relação ao letramento, deixando-se de perceber muitas das heterogeneidades sociais em relação à língua.

A terceira posição destacada pelo autor é a variacionista, que propõe aspectos específicos em relação à abordagem das variedades padrão e não padrão no ensino. $\mathrm{O}$ 
autor aponta como saliente nessa perspectiva o fato de não se buscar evidenciar diferenças entre fala e escrita, mas entre variedades linguísticas quaisquer. Os teóricos dessa vertente buscam mostrar que a decisão sobre qual das variedades será considerada a padrão é muito mais ideológica do que linguística. Junto a isso, outro aspecto a se destacar é que a variação se dá nas duas modalidades da língua, evitando-se, assim, a associação da escrita à língua padrão. Entretanto, o problema dessa perspectiva é a tentativa de desenvolver nos indivíduos um desempenho dialetal, o que seria impossível, segundo o autor.

A quarta perspectiva apresentada por Marcuschi é a sociointeracionista, que tem como princípio a visão da linguagem como interação. De acordo com essa visão, ambas as modalidades da língua apresentam dialogicidade, usos estratégicos, funções interacionais, envolvimento, negociação, situacionalidade, coerência e dinamicidade. Marcuschi destaca nessas teorias a possibilidade de analisar os fenômenos linguísticos em relação com as situações de interação, tomando-se os gêneros textuais e seus usos como um de seus objetos primordiais de estudo. Assim, esse ponto de vista distancia-se de algumas visões equivocadas anteriores, mas seria ainda necessário aprofundar as explicações de fenômenos próprios da língua.

Ao analisar cada uma dessas perspectivas, Marcuschi comenta que não há um consenso sobre as relações entre fala e escrita, e que isso se dá principalmente devido ao dinamismo que envolve essas duas modalidades. Afirma ele:

Discorrer sobre as relações entre oralidade/letramento e fala/escrita não é referir-se a algo consensual nem mesmo como objeto de análise. Trata-se de fenômenos de fala e escrita enquanto relação entre fatos linguísticos (relação fala-escrita) e enquanto relação entre práticas sociais (oralidade versus letramento). As relações entre fala e escrita não são óbvias nem lineares, pois elas refletem um constante dinamismo fundado no continuum que se manifesta entre essas duas modalidades de uso da língua. (MARCUSCHI, 2010, p. 34).

Dessa forma, faz-se necessário, conforme o autor, que a relevância tanto da oralidade quanto do letramento seja explicitada a partir das práticas de linguagem, por meio das quais são determinados o papel, o lugar e a importância de cada um; não se trata, pois, de uma relação oposta, mas sim situada num "contínuo sócio-histórico" de práticas.

A oralidade, então, é uma prática social com objetivos de interação definidos, que se manifesta em diferentes gêneros textuais por meios sonoros. A mesma pode variar entre formas mais ou menos formais, a depender do contexto de uso. Já a fala é, para Marcuschi, "uma forma de produção textual-discursiva para fins comunicativos na modalidade oral" (MARCUSCHI, 2010). A fala é caracterizada pela utilização da língua em forma de sons, com algumas características específicas, envolvendo aspectos prosódicos e outros recursos expressivos, como gestos e movimentos do corpo. A escrita, da mesma maneira, é uma forma de "[...] produção textual-discursiva para fins comunicativos com certas especificidades materiais e se caracterizaria por sua constituição gráfica..." (MARCUSCHI, 2010, p. 26). O mesmo autor define letramento como sendo as práticas sociais relacionadas à escrita, abarcando desde uma apropriação mínima até um domínio profundo da escrita, bem como a participação significativa em eventos de letramento. 
Assim, a maior diferença entre fala e escrita seriam os aspectos sonoro e gráfico, podendo essa visão ser ampliada no sentido de englobar "[...] na fala todas as manifestações textuais-discursivas da modalidade oral, bem como englobar na escrita todas as manifestações textuais-discursivas da modalidade escrita..." (MARCUSCHI, 2010 , p. 26, grifos do autor).

Isso posto, Marcuschi passa a destacar alguns aspectos interessantes de observar nessa relação. Primeiramente, salienta que a língua, tanto falada quanto escrita, "reflete, em boa medida, a organização da sociedade" (MARCUSCHI, 2010, p. 35, grifo do autor). Isso se dá devido às relações entre a língua e as representações sociais; é por meio da língua que os seres humanos podem constituir e firmar crenças e pontos de vista sobre os variados acontecimentos do mundo. Assim, junto à cultura, o que torna o ser humano mais peculiar dentre os demais seres vivos é "o fato de ele dispor de uma linguagem simbólica articulada que é muito mais do que um sistema de classificação" (MARCUSCHI, 2010, p. 35).

Outro ponto a ser levado em consideração é que nem a fala nem a escrita têm intrinsecamente aspectos positivos e negativos; assim, não há uma modalidade que seja superior à outra, sendo necessário, para que esses tipos de relações sejam estabelecidas, que se observe o que se está comparando e a heterogeneidade dessas relações, que variam conforme os usos. Além disso, o autor ressalta que a oralidade não desaparecerá e, junto à escrita, é um grande meio de expressão da atividade humana, sendo intrínseca ao ser humano e reflexo de fatores como identidade regional e social.

Em relação aos usos da língua, Marcuschi ressalta, de forma bastante enfática, que a utilização de uma ou de outra modalidade dependerá da situação, havendo práticas que são mais adequadamente mediadas pela escrita e outras pela modalidade oral da língua. Assim, "oralidade e escrita são duas práticas sociais e não duas práticas de sociedades diversas"(MARCUSCHI, 2010, p. 37, grifos do autor).

O autor propõe que se deixe de analisar a oralidade a partir do olhar com que sempre observamos a escrita, e que as diferenças entre ambas sejam percebidas dentro de um contínuo em que se situam variações de gêneros decorrentes das práticas sociais. Haveria, então, um gênero que seria o protótipo da fala (que não seria comparável a um gênero escrito), e outro que seria o protótipo da escrita; e ainda, alguns gêneros poderiam ser considerados mistos, por possuírem características de ambas as modalidades. Uma das questões centrais dessa discussão, segundo Marcuschi, é "[...] a impossibilidade de situar a oralidade e a escrita em sistemas linguísticos diversos..." (MARCUSCHI, 2010, p. 38), já que se trata de diferentes realizações de uma mesma gramática, mas com peculiaridades que fazem com que uma modalidade não seja a representação da outra.

Tendo esses aspectos em mente, Marcuschi elaborou um gráfico (Figura 1) para representar o contínuo dos gêneros textuais em relação à fala e à escrita, distinguindo-os em relação à estratégia de formulação e destacando o fato de que ambas as modalidades variam. 


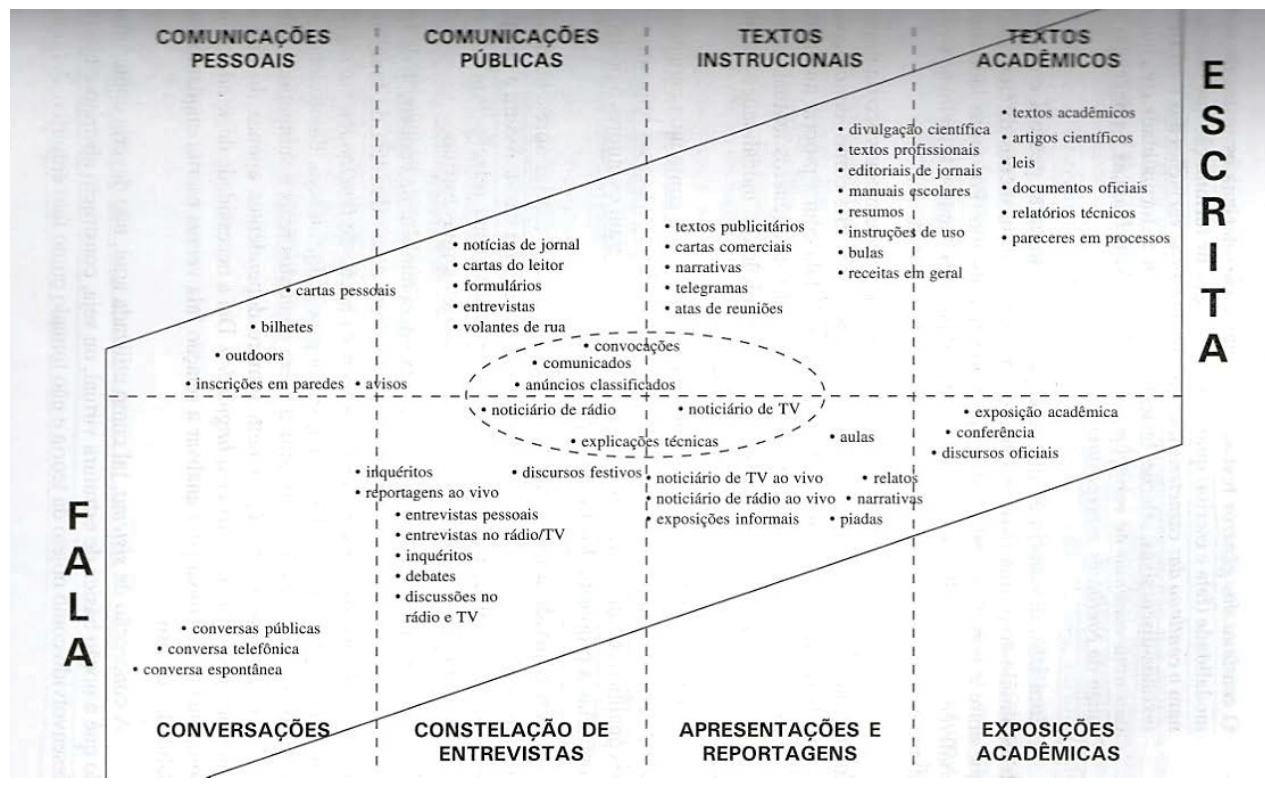

Figura 1: Gráfico representativo do continuum fala e escrita Fonte: MARCUSCHI, 2010

Com vistas a explicar sua hipótese acerca das relações entre fala e escrita de um ponto de vista sociointeracional, Marcuschi afirma:

O contínuo dos gêneros textuais distingue e correlaciona os textos de cada modalidade (fala e escrita) quanto às estratégias de formulação que determinam o contínuo das características que produzem as variações das estruturas textuais-discursivas, seleções lexicais, estilo, grau de formalidade, etc., que se dão num contínuo de variações, surgindo daí semelhanças e diferenças ao longo de contínuos sobrepostos. (MARCUSCHI, 2010, p. 42, grifos do autor).

Assim, ele busca explicar que ambas as modalidades variam em um continuum, e a comparação entre elas deve ser pautada nesse continuum, que envolve as condições de produção e uso da língua.

A respeito das relações entre fala e escrita Fávero, Andrade e Aquino (1999) colocam-se junto à perspectiva de Marcuschi, ao afirmar que as duas modalidades situam-se em um continuum que vai do menos para o mais formal. As autoras ressaltam as dificuldades de se relacionar fala e escrita, na medida em que tipologias anteriores foram estabelecidas sem que tivessem sido realizadas análises mais aprofundadas dos gêneros de cada modalidade que se corresponderiam nesse continuum.

Fávero, Andrade e Aquino realizam, a partir disso, um apanhado de alguns estudos que abordam essas relações, destacando que a língua falada não possui uma gramática diferenciada da escrita, mas que suas formas de concretização é que são distintas.

Segundo elas, algumas pesquisas apontam como especificidades da língua falada a menor quantidade de palavras (as quais, em geral, têm menos sílabas) e frases mais curtas, além de maior quantidade de palavras de referência. Outro ponto importante é que há fatores como contexto e objetivo da comunicação, e características dos participantes e seu grupo social que afetam a escolha lexical - tal qual no texto escrito - 
e que é preciso tê-los em conta no momento da análise de um texto, tanto falado quanto escrito.

De acordo com a literatura analisada pelas autoras, as grandes diferenças existentes entre fala e escrita se dão devido aos aspectos particulares de cada tipo de texto analisado. Assim, no mesmo sentido que Biber (1988) apud FÁVERO et al., (1999), as autoras afirmam que "[...] essas diferenças se acentuam dentro de um continuum tipológico..." (FÁVERO et al. 1999, p. 75), o qual variaria de textos mais informais até os mais formais, podendo haver textos informais tanto na fala quanto na escrita.

Paralelamente à visão de Biber, as autoras trazem a abordagem de Ochs (1979) apud FÁVERO et al., 1999), que classifica os textos em quatro tipos, nessa mesma perspectiva: falado não-planejado, escrito não-planejado, falado planejado e escrito planejado, destacando que há na língua falada uma tendência para o não-planejado, ou para o planejamento local, no momento da concretização da interação. Para fundamentar essa afirmação sobre o planejamento local da fala, as autoras utilizam-se da teoria de Chafe (1982) apud FÁVERO et al., (1999), que cita como características da fala a fragmentação (em oposição à integração mais típica da escrita) e o envolvimento (oposto ao afastamento, também mais comum na modalidade escrita da língua).

No mesmo sentido dessas distinções elaboradas por Chafe (idem), Biber (1988) apud FÁVERO et al., 1999) classifica os textos em quatro diferentes formas, também em um contínuo que se aproxima das relações entre fala escrita: "[...] muitas pronominalizações e passivas, poucas nominalizações e passivas, muitos pronomes e contrações, poucos pronomes e contrações..." (BIBER, 1988 apud FÁVERO et al., 1999, p. 78). Essa classificação, como se observa, pauta-se em aspectos textuais mais estruturais.

As autoras destacam, então, que, apesar de muitos autores já haverem tratado dessa questão das relações entre fala e escrita, suas abordagens não foram eficazes, uma vez que as modalidades não foram descritas de modo adequado ou foram relacionadas a extremos, em geral baseados na valorização da escrita. Apesar dessa consideração, percebe-se ainda que, em muitos momentos do texto das autoras, principalmente nos exemplos que trazem, as condições de produção não são levadas em conta e a oralidade é associada de forma generalizada à conversação espontânea, o que contribui para que algumas concepções que elas mesmas consideram equivocadas sejam reforçadas em suas abordagens.

Em outro texto, Fávero et al., (2011) já revelam mudança nessa perspectiva, ao afirmarem que ambas as modalidades apresentam as características de "dialogicidade, usos estratégicos, funções interacionais, envolvimento, negociação, situacionalidade, coerência e dinamicidade" (FÁVERO et al., 2011), situando-se em um contínuo por meio do qual devem ser analisadas a partir dos usos em situações de comunicação. Além disso, defendem a necessidade de termos em mente que algumas das diferenças entre a oralidade e a escrita podem ser devidas às escolhas do enunciador, as quais dependem das especificidades da situação de uso e dos gêneros textuais a serem utilizados. As autoras ainda consideram que, uma vez que toda atividade de linguagem se constitui por uma interação, esta é que deve ser observada ao se analisarem produções orais e escritas. 
Outro ponto que as autoras destacam para mostrar que as diferenças entre as duas modalidades estão situadas nos usos é o fato de que, cognitivamente, o processamento do texto escrito e o do texto oral apresentam vários aspectos similares, sendo a interatividade uma estratégia que pode ocorrer em ambas as modalidades da língua. As autoras afirmam, também, que a escrita e a oralidade não podem ser pensadas como invariantes, uma vez que há diferenças causadas pela diversidade de condições de produção e situações comunicativas.

Dolz et al., (2004) destacam, por sua vez, o fato de que a escrita não pode ser substituta do oral, e buscam esclarecer que a consideração generalizada da fala como algo mal estruturado e da escrita como o fundamento normativo da língua faz com que sejam ignoradas as diferentes possibilidades de uso da mesma nos mais diversos contextos; ou seja, nessa perspectiva, desconsidera-se o fato de que tanto na oralidade como na escrita podem existir formas mais ou menos formais, padrão e não padrão.

Os autores, apesar de acharem que há diversos tipos de oral, tanto espontâneos quanto mais formais, julgam importante diferenciar dois tipos que têm características muito diferentes: o oral espontâneo, cujas características mais marcantes são a fragmentação e a descontinuidade, embora se tenha vários aspectos de regularidade em sua produção; e a oralização da escrita, que é dependente de um texto escrito e limitada a ele. Entre esses dois "orais" extremos, situar-se-iam todos os outros orais.

Schneuwly (2004) afirma que, tomando-se o oral como multiforme, não haveria oposição entre oral e escrita; nem, da mesma forma, uma definição uniforme da oralidade em relação à escrita, uma vez que não existe "o" oral, mas "os" orais, que se materializam por meio dos gêneros nos quais se utiliza por essência a modalidade oral da língua.

Da mesma forma, Antunes (2003) propõe termos em mente que, apesar das especificidades das modalidades oral e escrita da língua, não se encontram diferenças essenciais nas mesmas, uma vez que as duas são utilizadas para a concretização da interação verbal. Ambas as modalidades se constituem por meio de diferentes gêneros textuais, de forma diversificada, não havendo sentido em classificar a fala como espontânea, relaxada e sem planejamento, e a escrita como uniforme e correta.

A partir das visões desses autores, consideramos, portanto, a oralidade como uma modalidade da língua que possui características particulares e que, pelo meio sonoro, configura-se por meio de práticas sociocomunicativas definidas por objetivos específicos e situadas em um contínuo. No que concerne especificamente às relações entre fala e escrita, acreditamos que elas são modalidades da língua que se fazem presentes de forma integrada na sociedade. Elas podem se concretizar de múltiplas formas, mais ou menos formais, e, por isso, não podem ser vistas de maneira dicotômica, mas sim, numa perspectiva sociointeracionista, por meio dos contextos de interação e de forma situada sócio-historicamente. Para que tal visão seja possível, fazse necessário conceber essas relações em um continuum de gêneros textuais em que ambas as modalidades variam. 


\section{A ABORDAGEM DAS RELAÇÕES ENTRE ORALIDADE E ESCRITA NA ESCOLA}

Concordamos com Milanez (1993) em que é preciso que ocorra uma transformação no ensino no sentido de integrar as modalidades oral e escrita da língua, trabalhando-se com as diversas formas orais e escritas existentes, especificamente aquelas da variedade padrão.

Focando em particular as relações entre fala e escrita a partir de seus usos, Marcuschi (2010) propõe que, para que se analise o grau de consciência dos indivíduos sobre as relações entre fala e escrita, sejam realizadas atividades de transformação de uma modalidade para a outra, ou seja, atividades de retextualização, as quais são um processo que interfere no código e em outros aspectos não muito evidentes nas relações entre fala e escrita.

O autor destaca a importância dessas atividades no ensino, visto que elas podem proporcionar conhecimentos sobre o texto oral e o texto escrito, além de acabar com algumas ideias distorcidas sobre as relações entre fala e escrita. As atividades de retextualização contribuem também para a percepção de que a fala não deve ser diretamente associada ao caos. Diz Marcuschi: “[...] o texto oral apresenta nos diversos gêneros alto grau de coesividade e coerência, não podendo ser tido como desordenado ou fragmentário...” (MARCUSCHI, 2010, p. 124).

Fávero et al., (1999) filiam-se a essa perspectiva de Marcuschi, afirmando que o ensino da fala deve se concretizar no sentido de fazer com que os alunos percebam a diversidade de situações em que a modalidade oral da língua é utilizada, e se conscientizem de que essas situações dão à linguagem um caráter heterogêneo, mais ou menos formal, a depender da situação. Uma vez que a oralidade e a escrita mantêm relações mútuas entre si, não é possível conceber o ensino da oralidade de maneira isolada e sem relações com a escrita. De acordo com as autoras, o que interessa para o ensino é que os alunos se apropriem de ambas as formas de produção textual, sendo capazes de "organizar sua atividade linguística de modo consciente, sem que façam interferir uma formulação de língua falada em outra de língua escrita se assim não o desejarem." (FÁVERO et al., 1999, p. 82-83).

Também se observam influências da proposta de Marcuschi na perspectiva de Crescitelli e Reis (2011), que se valem do conceito de retextualização, mas vão além. Acreditando que o ensino deve ser inclusivo, democrático e de qualidade, as autoras colocam a valorização da fala como meio de abarcar a língua como um todo, uma vez que esta se constitui de ambas as modalidades, a oral e a escrita. $\mathrm{O}$ ensino de oralidade deveria, assim, de acordo com as autoras, receber um tratamento semelhante ao que é dado à escrita. Elas afirmam que, num ensino que privilegia a escrita, como ocorre atualmente, a oralidade é enxergada como algo incompleto, um objeto sem autonomia, sem tanto valor social por si só, ou seja, trata-se de um objeto dependente da escrita. Por isso, consideram necessário ter em conta que a valorização da escrita só se dá devido a posturas ideológicas de alguns grupos, isto é, a supremacia da escrita não se dá por fatores específicos dessa modalidade da língua. 
Considerando esses aspectos, propõem que o ensino da escrita, que é de extrema importância, não deveria ocorrer em detrimento do da oralidade, uma vez que a língua é bimodal. O ensino da oralidade deveria ocorrer, então,

[...] por meio da análise de falas contextualizadas, em interações face a face ou em falas individuais, preferencialmente gravadas, para se verificar o funcionamento da língua viva em pleno uso, sobretudo por possibilitar o acolhimento das variantes linguísticas que chegam à escola. (CRESCITELLI e REIS, 2011, p. 31).

Nesse sentido, Milanez (1993) acredita que, uma vez que o papel da escola é permitir que o aluno se aproprie das diferentes formas de utilização da língua, o professor deve mostrar, desde o início da escolarização, as diferenças entre as modalidades oral e escrita da língua, junto às diferenças entre as variedades linguísticas.

Ao considerarmos a modalidade oral da língua como um objeto de ensino, em uma concepção interacionista de língua, acreditamos que, tal como ocorre com relação à escrita, o ensino da oralidade deve se efetivar também a partir do texto. Uma vez que nenhuma dessas modalidades da língua se realiza de forma isolada na sociedade, acreditamos também que o ensino deve articulá-las, valorizando suas relações. $O$ trabalho com a oralidade ainda deve considerar a diversidade de situações em que a modalidade oral é utilizada, a fim de possibilitar que o aluno passe a conhecer e utilizar novas e diferentes formas de concretização da linguagem, que vão além daquelas a que ele já tem acesso.

\section{METODOLOGIA}

A pesquisa aqui relatada, qualitativa e de cunho etnográfico, foi realizada a partir de observações de 28 dias de aulas de uma professora da Rede Estadual de ensino do Estado de Pernambuco. Tal professora foi selecionada por meio de um questionário aplicado junto a alguns professores da rede de ensino já mencionada, com a finalidade de encontrar aqueles abordassem de forma sistemática os gêneros orais em suas aulas. Para coletar os dados, realizamos uma observação participante, assim chamada, de acordo com André (2008), por pressupor uma maior interação com os sujeitos da pesquisa. Nessas aulas foram realizadas anotações em diários de campo e gravações em áudio, em aparelhos MP4, que permitiram registrar, inclusive, o posicionamento da professora em relação ao tema no momento do trabalho em sala de aula.

Para a análise dos dados coletados nas observações, levamos em conta: as concepções de linguagem e oralidade implícitas na prática da professora; os procedimentos didáticos adotados e as metodologias empregadas em relação ao trabalho com os gêneros orais; a abordagem da variação linguística e das especificidades do oral; e a articulação, caso houvesse, entre o trabalho com os gêneros orais e as práticas de leitura, produção textual e análise linguística. No presente artigo, vamos priorizar a abordagem realizada pela professora em relação à modalidade oral da língua e a suas relações com a escrita.

A professora selecionada é formada em Letras pela Universidade Federal de Pernambuco e possui mestrado pela mesma universidade, também na área de Letras. Logo no início da pesquisa, destacou o fato de ter realizado, durante sua graduação, pesquisa de iniciação científica com a equipe dos professores Luiz Antonio Marcuschi, 
Doris Cunha e Judith Hoffnagel, que investigavam questões voltadas à conversação. Na escola em questão, além de assumir a disciplina de língua portuguesa, a professora também dá aulas de artes, embora não tenha formação específica nessa área de conhecimento. Junto a isso, ela também trabalha em uma escola da rede particular de ensino da cidade do Recife.

\section{DESCRIÇÃO E ANÁLISE DAS AULAS}

Observamos a professora participante da pesquisa durante 28 dias, entre os meses de julho e novembro de 2012, sendo a maioria das aulas geminadas, exceto quando ocorriam problemas relacionados à organização da escola. A turma em questão, um $7^{\circ}$ ano do ensino fundamental, era composta, em sua maioria, por alunos oriundos da comunidade em que a escola se situa.

As aulas observadas foram referentes ao trabalho com o projeto Olimpíada de Língua Portuguesa $^{2}$ - o qual envolvia os gêneros textuais memória literária e entrevista; além dessas, vimos outras em que foram tratados os conteúdos advérbio e verbo, que, embora a professora tenha tentado articular com a abordagem dos gêneros, foram explorados de forma relativamente isolada dos demais conteúdos.

Para a feitura do presente artigo, optamos por destacar as aulas em que a professora focou a produção do gênero entrevista porque nelas ficou mais evidente a maneira como foram abordadas as relações entre fala e escrita. Dentre os procedimentos metodológicos voltados especificamente para o gênero entrevista, identificamos duas sequências didáticas relevantes. A primeira delas constituiu-se como uma experiência mais individual dos alunos com o gênero, embora em alguns momentos o trabalho tenha sido feito em pequenos grupos, enquanto a segunda foi realizada em uma perspectiva tipicamente coletiva. A seguir, realizaremos a descrição de cada uma das sequências de aula, seguida de suas respectivas análises.

\subsection{Primeira Sequência de Aulas}

Quadro 2: Etapas da primeira sequência de aulas

1. Leitura de memória literária e reflexão sobre as condições de produção desse gênero. Discussão sobre como a autora do texto conseguiu informações para escrever a história de outrem.

2. Em grupos, produção de entrevista com pessoa mais velha da comunidade sobre algum fato marcante de sua vida.

3. Em grupos, sistematização dos dados obtidos na entrevista a partir da construção de um quadro.

4. Apresentação das histórias obtidas por meio das entrevistas, com retomada de questões que não haviam ficado claras.

5. Atividade do livro didático sobre marcas da oralidade na entrevista.

Nessa primeira sequência, o objetivo maior da realização das entrevistas era a produção de memórias literárias. Assim, foi a partir de um texto do gênero memória literária que a professora iniciou o trabalho. Primeiramente, leu-se o texto "O valetão que engolia meninos e outras histórias de Pajé”3. Em seguida, a professora fez várias perguntas de

\footnotetext{
${ }^{2}$ A Olimpíada Brasileira de Língua Portuguesa é um projeto desenvolvido pelo Ministério da Educação, no âmbito do qual, bienalmente, são realizados concursos de produção de textos de alunos e ações de formação de professores voltadas para o ensino de leitura e produção de textos na escola.

${ }^{3}$ Texto produzido no contexto da Olimpíada de Língua Portuguesa por uma aluna campeã de uma edição anterior do projeto.
} 
compreensão do texto e, por fim, introduziu a discussão sobre a forma como aquele texto foi produzido, mostrando aos alunos que, para escrever aquela história, a autora precisou escutar alguma pessoa mais velha, fazer perguntas para aprofundar a história e, assim, conseguir informações relevantes. A partir daí, ela buscou levar os alunos a compreender a composição daquele texto, para que eles percebessem o que precisariam fazer para também escrever suas memórias literárias.

\section{AULA 3}

P: Agora a gente vai pensar em como fazer uma conversa com uma pessoa mais velha [...] A nossa ideia é que a gente consiga aprender com a experiência do mais velho, certo? A gente vai montar um grupo com no máximo quatro pessoas e vai conversar com uma pessoa mais velha da comunidade. Nessa conversa a gente vai perguntar se essa pessoa lembra de algum fato, de alguma passagem, de algum acontecimento marcante na vida dessa pessoa. [...] A gente conversou sobre o texto e mostrou que ele foi produzido exatamente da mesma forma que o texto que a gente vai produzir, a gente vai conversar com o mais velho pra poder ter informações pra escrever o texto. [...] são as mesmas condições de produção. A gente vai conversar com um mais velho e vai perguntar a ele: o que foi de marcante que aconteceu na sua vida? Vai que ele conta alguma coisa parecida com essa que a gente acabou de ler. (...) Quando a gente leu o texto sobre o valetão, a gente conseguiu imaginar o lugar? [...] E como eram aqueles personagens, a engraxadeira, a chuva, enfim, por quê? Como foi que essa pessoa conseguiu essas informações?

A: Porque ela perguntou.

Podemos perceber que a professora buscou articular o trabalho em sala de aula com textos das modalidades oral e escrita da língua, salientando que ambas se fazem presentes na sociedade de forma complementar.

A primeira entrevista realizada pelos alunos foi concretizada fora da escola, em grupos, a partir da discussão realizada em sala. Em momento posterior, a professora encaminhou a sistematização dos dados obtidos a partir das entrevistas em categorias propostas por ela e, em seguida, eles começaram a expor as informações angariadas.

As histórias que os alunos contaram a partir das entrevistas foram muito interessantes, como a de um pescador que quase foi engolido por uma baleia, e a de outro que, ao pescar, deixou sua vara cair na água e, na tentativa de recuperá-la, perdeu o barco; ou, ainda, de uma criança que morreu no mar porque tentou passar por baixo dos arrecifes e ficou com o pé preso. Fica bastante claro que, por meio dessa atividade, os alunos trouxeram para a sala de aula elementos muito fortes da identidade da comunidade em que viviam, como a ligação com o ara $^{4}$.

A partir das histórias, observamos que, inclusive, os alunos que nunca participavam da aula, procuraram espontaneamente se posicionar em relação ao que era discutido. Assim, observamos, conforme Braun (2003, p. 41), que:

[...] a adoção da língua oral como objeto de ensino-aprendizagem permite que a aula se abra ao debate e à discussão de temas que envolvam os interesses dos alunos. (...) [a aula] cumpre também sua função de socialização ao viabilizar a possibilidade de integração dos indivíduos e ao colocar entre seus objetivos o desenvolvimento de competências ordinárias que ultrapassam em muito o universo escolar. A aprendizagem só adquire sentido e permanência quando garante ao

\footnotetext{
4 Trata-se da comunidade de Brasília Teimosa, localizada em Recife-PE, formada por pescadores e bastante conhecida pela resistência da população em permanecer na área, apesar de esforços do governo para retirá-la do local.
} 
aluno o aprimoramento da capacidade de expressar-se como indivíduo e cidadão.(BRAUN, 2003, p.41).

O trabalho com o gênero entrevista, portanto, possibilitou que os alunos se vissem representados e efetivamente participantes da construção de discursos na sala de aula. Finalizadas as apresentações dos alunos, a professora questionou-os sobre o processo de produção da entrevista: se eles escreveram, gravaram, transcreveram etc. Como alguns alunos disseram que tiveram problemas com ruídos na gravação, ela chamou atenção para a necessidade de preparar o ambiente para a entrevista e destacou algumas particularidades do texto oral:

\begin{abstract}
AULA 6
P: Quando eu leio o texto escrito, eu já pego esse texto pronto, não é? Ao contrário do que acontece com o texto produzido oralmente: à medida que eu vou planejando eu vou produzindo, então quem recebe, quem ouve esse texto, quem participa dessa conversação da entrevista vai percebendo o planejamento, e esse planejamento é percebido pelo quê, por exemplo? Ahn... na minha fala eu faço uma pausa. Por quê? Porque eu estou pensando - ahn...; como é mesmo; ah, melhor dizendo... não é isso? [...] Por que eu faço esses alongamentos? Porque eu estou pensando no que eu vou dizer, qual é a palavra que eu vou usar [...] A gente vive nessa dinâmica, na produção oral, de refletir sobre e reproduzir ao mesmo tempo. E quem recebe vê o contexto exatamente do jeito que ele está sendo produzido. A gente diz assim: on-line. Não é assim: eu penso, produzo, escrevo e aí mostro pra vocês o texto oral. Não é assim! Isso acontece com o texto escrito. Então essa necessidade de planejar e produzir ao mesmo tempo faz com que o texto falado tenha uma série de pausas, alongamentos, reformulações.
\end{abstract}

Em seguida, a professora demonstra ter uma postura similar à de Marcuschi e Dionísio (2005), quando eles afirmam: "fala e escrita são realizações de um mesmo sistema linguístico de base, mas com realização, história e representação próprias" (MARCUSCHI e DIONÍSIO, 2005, p.16, grifo dos autores). A partir dessa percepção, a professora comenta com os alunos as diferentes estratégias utilizadas na oralidade, conforme podemos observar no trecho a seguir:

\title{
AULA 6
}

$P:[. .$.$] as estratégias que a gente usa para falar são diferentes das que a gente usa para escrever, né?$ Por exemplo, enquanto eu estou falando agora, eu estou pensando e falando ao mesmo tempo, né isso? Se eu cometer algum erro, se eu esquecer alguma coisa, que é que eu vou fazer? [...] Elaborar uma nova frase, uma nova fala, e continuar daí. Então, isso tem a ver com as condições de produção da fala, do texto falado e dos textos produzidos escrevendo, né isso? Quando a gente está falando, ouvindo, a gente vai pensando no que vai dizer, ou seja, planejando, e vai produzindo, mas isso não é uma coisa consciente não. [...] Então, as condições da minha produção oral são um pouquinho diferentes da escrita.

Apesar de considerar tais modalidades como diferentes, a professora faz questão de deixar claro para os alunos que não se deve valorar uma modalidade da língua mais do que a outra, e que ambas proporcionam experiências linguísticas distintas. Por esse caminho, ela questiona o princípio da "supremacia atribuída à escrita" (MARCUSCHI e DIONÍSIO, 2005) e mostra que, na oralidade, ainda que esta esteja representada em um texto escrito, também há fenômenos linguísticos que merecem reflexão e que são passíveis de didatização:

\section{AULA 7}

P: A modalidade oral, por conta da tradição de trabalhar a escrita na escola, fica relegada a segundo plano. A gente não tem esse hábito de trabalhar com a modalidade oral. Às vezes a gente até acha 
estranho, né, o texto oral, porque a gente não tem hábito de trabalhar com ele. Mas eu não sei se vocês se deram conta de quando a gente leu aquela canção, a gente percebeu muita coisa a respeito de como a gente fala, não é? E que esse sistema que organiza a forma como a gente fala é diferente da organização do texto escrito.

Em seguida a essa discussão, a professora parte para uma atividade do livro didático (LD) que leva os alunos a refletirem sobre as marcas da oralidade na entrevista. Trata-se de uma seção que discute diversos aspectos relacionados à oralidade. Nesta, especificamente, são trazidos dois textos - uma transcrição de entrevista do $\mathrm{NURC}^{5} \mathrm{e}$ uma entrevista escrita com Maurício de Souza - a partir dos quais são destacadas determinadas especificidades da modalidade oral da língua.

$\mathrm{Na}$ discussão do primeiro texto, a professora, ao explicar detalhadamente o projeto NURC, enfatiza que a entrevista produzida nesse projeto foi concebida com um objetivo diferente do daquela que eles haviam realizado. Os entrevistadores do NURC têm o objetivo de analisar a fala dos entrevistados, e aquela feita pelos alunos objetivava coletar informações. É a partir dessa atividade, portanto, e depois que os alunos já produziram a primeira entrevista, que eles têm acesso, na sala de aula, a um texto do gênero entrevista e discutem um pouco de suas características.

Abaixo do texto, vem, no LD, um quadro com explicações sobre os sinais usados na transcrição da fala na entrevista, os quais a professora discute detalhadamente com os alunos. A partir das explicações sobre os sinais utilizados para representar a linguagem oral nas transcrições, a docente, mais uma vez, leva os alunos a refletirem sobre as semelhanças e diferenças entre as modalidades oral e escrita da língua:

AULA 6
P: Na fala, a gente não vai colocar vírgula, ponto e vírgula, ponto final, porque essas são notações,
são sinais que a gente usa na escrita. A modalidade oral é uma coisa, e a modalidade escrita é outra.
Cada uma tem a sua estrutura, suas estratégias, enfim. Além disso, a pausa na fala é bem diferente da
pausa na escrita, né? A pausa na escrita, ela tem funções sintáticas, inclusive, né? Ela tem uma
relação com a organização das palavras na frase, com regras, obedecem a regras da variedade
padrão em relação a essa sintaxe da língua. Nós ainda não estudamos a respeito da sintaxe, né, mas a
gente já viu ano passado sujeito, predicado, não foi? Então quando a gente viu sujeito, predicado, uma
das coisas que a gente viu foi que a gente não usa vírgula pra separar o sujeito do predicado. Porém,
na oralidade, isso é feito. Então, as estratégias da oralidade e da escrita são bem distintas. Na fala, a
gente pode até fazer uma pausa entre o sujeito e o verbo, por exemplo: João... fez supermercado
ontem. Por quê? Porque eu tô pensando um pouquinho ainda sobre o que eu vou dizer. Tem uma pausa
aí no meio, separando o sujeito e o predicado. Tá certo? Mas na escrita isso não poderia acontecer.
Por que, afinal, na escrita tem essa pausa? A gente para pra ficar pensando na escrita? Não. A gente
pensou antes de produzir e não tem que mostrar essa reflexão no texto, certo? Então por isso as pausas
são mostradas de um jeito diferente na fala e na escrita.

Procedendo conforme a descrição acima, a professora assume uma postura que vai ao encontro do que propõem Dolz, Schneuwly e Haller (2004), os quais acreditam que o ensino da expressão oral não deve se pautar exclusivamente nas características da fala, mas, sim, voltar-se para o conhecimento das diversas práticas de linguagem que envolvem a oralidade, bem como suas relações com a escrita. Assim, de acordo com os autores, a fim de que o oral seja constituído como objeto de ensino, é necessário que

\footnotetext{
${ }^{5}$ O Projeto NURC - Norma Linguística Urbana Culta - teve início em 1970 com o objetivo de caracterizar a modalidade culta da língua falada de cinco grandes centros urbanos brasileiros - Recife, Salvador, Rio de Janeiro, São Paulo e Porto Alegre.
} 
sejam caracterizados os saberes a serem trabalhados e as especificidades linguísticas das práticas que constituirão esse trabalho.

A partir da atividade do LD, a professora realiza junto com os alunos a análise linguística do texto oral transcrito, que é a forma escrita que permite que o maior número de características da oralidade seja mantido. Assim, eles puderam observar a importância de especificidades do oral, como pausas e alongamentos, para a construção do sentido do texto.

\subsection{Segunda Sequência de Aulas}

Quadro 3: Etapas da segunda sequência de aulas

1. Reunião dos alunos em grupos para a preparação de um roteiro de perguntas para a entrevista coletiva sobre temas sugeridos pela professora; discussão sobre regras da produção do gênero entrevista.

2. Realização de entrevista coletiva com a avó de uma das alunas.

3. Leitura de trecho de anotações sobre entrevista; reflexão coletiva sobre os passos necessários para retextualizar a entrevista em um texto do gênero memórias literárias.

4. Transcrição de um trecho da entrevista para identificar as características da modalidade oral da língua.

Nessa segunda sequência de aulas, a professora propõe que os alunos realizem, conjuntamente, uma entrevista com um membro mais velho da sociedade. Após escolherem quem seria o entrevistado, a partir da disponibilidade dos familiares dos alunos, a professora iniciou o processo de elaboração de um roteiro de entrevistas. Nessa preparação, houve um momento em que ela solicitou que os alunos refletissem sobre a linguagem a ser utilizada na entrevista. Ao contrário do que geralmente ocorre em relação a esse gênero, em situações jornalísticas, por exemplo, quando se busca utilizar uma variedade mais formal da língua, ela pede que eles procurem ser mais informais, no intuito de serem menos artificiais:

AULA 20
P: Agora vejam só. Uma coisa que eu quero conversar com vocês é o seguinte, a gente precisa tornar
essas perguntas o mais próximo possível da oralidade. Por quê? A gente vai ter uma conversa com
essa senhora. Então para que as perguntas não fiquem parecendo, assim, muito formais, né? Procurar
sempre a forma mais simples de dizer, porém bastante explicativa. Por exemplo, como era o ensino
naquela época? Como eram as escolas? O que é que a senhora achava dos professores? A senhora
pode falar um pouco sobre isso? Não é "como eram as escolas e professores naquela época?"
[professora fala um tom de voz formal para mostrar a seriedade da pergunta]. Ela não é candidata a
prefeita, não. Eu quero que vocês façam perguntas de maneira bem informal, como se a gente estivesse
fazendo uma conversa.

Apesar de a utilização da expressão "o mais próximo possível da oralidade" poder levar a uma sensação de dicotomia em relação à escrita, o que a professora pretendia realmente era uma adequação à situação de comunicação, para a qual os alunos precisariam ajustar o discurso e a variedade da língua a ser utilizada. Isso é esclarecido quando ela mostra, em relação à entrevistada, que "ela não é candidata a prefeita", ou seja, se fosse em outra situação, os alunos precisariam se colocar de maneira distinta.

$\mathrm{Na}$ realização da entrevista, percebemos um esforço dos alunos por seguir as orientações da professora e o roteiro que havia sido elaborado. Nas aulas seguintes, a professora iniciou com os alunos uma discussão sobre o que fariam com o texto oral 
produzido. Assim, ela retomou o percurso eles que seguiram para a produção, partindo do planejamento, lembrando-lhes os objetivos que tinham e enfatizando que a entrevista que produziram constitui-se como um texto oral e, como tal, tem características específicas. A partir disso, retomou a atividade de retextualização previamente desenvolvida e perguntou o que precisariam modificar no texto oral para transformá-lo em um texto escrito:

\section{AULA 23}

P: Mas se a gente precisar passar esse texto oral, retextualizá-lo, ou seja, reconstruí-lo em uma outra modalidade de língua, a gente vai precisar eliminar estas estruturas características da modalidade oral. A gente vai precisar, por exemplo, eliminar tudo que for hesitação. Mas o que é que vai permanecer? Me digam aí. Dá pra vocês imaginarem o que é que a gente conservaria? O que a gente levaria para o texto escrito?

A: $O$ assunto mais importante.

P: Muito bem. O assunto mais importante. Então a gente vai observar a entrevista com atenção $e$ perceber qual é o assunto mais importante, o que é que tem, quais as informações mais importantes e conservar essa essência, né? Essas ideias principais, as informações mais importantes e eliminar tudo aquilo que for característico da modalidade oral, certo? Da fala.

$\mathrm{Na}$ sequência, a professora leva os alunos a mobilizarem os conhecimentos que possuem sobre os dois gêneros - entrevista e memórias literárias - para que possam pensar em operações adequadas para a retextualização.

\footnotetext{
AULA 23

P: Olha, mas eu preciso me lembrar de algumas características das memórias literárias. Primeiro...

A: Falar em primeira pessoa.

P: Muito bem, isso aí. Ele não vai falar do senhor Amalfe. Que é que ele vai fazer? Ele vai assumir, vamos dizer assim, a personalidade do senhor Amalfe, né isso? Ele vai se colocar no lugar do senhor Amalfe. Por isso, ele vai usar a primeira pessoa. Mas me diga uma coisa, pra que eu transforme isso que é uma entrevista em um texto de memórias literárias, o que mais eu preciso fazer? Uma entrevista se caracteriza pela presença de perguntas e respostas, não é isso? Pois bem, o que preciso para transformar uma entrevista em um texto de memórias literárias?

A: Vai tirar todas as perguntas dele, escutar todas as respostas dele e transformar em uma memória literária.

P: A primeira atitude que a gente tem que realmente fazer é essa, eliminar as perguntas. Por quê?? Quem sabe dizer?

A: (incompreensivel)

P: Exato. Porque essa é a característica essencial da entrevista, né? A gente tem perguntas e respostas. Nas memórias literárias não tem perguntas e respostas.
}

A importância de atividades como essa é destacada por Marcuschi (2010), uma vez que elas possibilitam que diversas habilidades relacionadas à utilização da língua sejam desenvolvidas. $\mathrm{O}$ autor ressalta que a atividade de retextualização não tem um caráter de ordenação, mas sim de mudança de uma ordem para outra. Além disso, ele defende que essas são também atividades de compreensão, uma vez que se faz necessário compreender um texto para transformá-lo. Outro ponto destacado nesse sentido é que a atividade de retextualização é diferente da de transcrição, uma vez que a última apenas transforma a realização sonora em gráfica por meio de convenções, sem interferir no conteúdo e na linguagem utilizada. Já na retextualização, há mudanças principalmente em relação à linguagem utilizada, em função de vários fatores, como os objetivos do texto e as mudanças entre o autor do texto original e do texto retextualizado. Esses fatores determinarão mudanças na forma e no conteúdo dos gêneros que serão definidos no processo de retextualização, bem como nas estratégias a serem utilizadas na produção do texto retextualizado. 
Percebemos que, assim procedendo, a docente leva os alunos a refletirem não só sobre as características dos gêneros, mas também sobre a linguagem a ser utilizada em função desses gêneros. A questão da compreensão do texto também é posta em relevo quando os alunos afirmaram que teriam que manter as informações mais importantes ao retextualizar.

Por fim, nessa sequência, a professora realizou, de forma coletiva, a transcrição de parte da entrevista produzida, objetivando que os alunos tivessem maior clareza das características da modalidade oral da língua. Assim, eles eram levados a ouvir o texto e a professora pausava-o a fim de tecer comentários ou de dar tempo para que pudessem realizar o ato de transcrição em si. Ainda que, conforme Marcuschi (2010), a atividade de transcrição não envolva tantas habilidades quanto a de retextualização, ela serve para que as características da oralidade sejam evidenciadas e, assim, possibilita que os alunos tenham maior clareza em relação a essas características, até mesmo para que depois realizem a retextualização de forma mais madura.

\section{AULA 25}

P: Nesse caso o texto tá escrito? Não. O texto não está escrito, ele é falado. A gente vai passá-lo, exatamente como ele... quer dizer, vai tentar reproduzir, usando um determinado conjunto de regras, a fala de Dona Sandra, ok? A gente vai reproduzir na modalidade escrita o texto que está na modalidade oral, tentando... utilizando algumas notações de transcrição, tentando reproduzir essas características da fala. Então a gente vai transcrever o texto pra poder compreender as características da modalidade oral da língua, da modalidade falada da língua, ok? Pra isso, vamos primeiro ouvir e depois a gente vai transcrever.

Acreditamos que a ordem em que as atividades de retextualização e transcrição foram realizadas poderia ter sido alterada, mas ainda assim ambas tiveram sua relevância no processo de construção de conhecimento dos alunos sobre a modalidade oral. Mediante a transcrição, após a escuta do texto oral, a professora pôde trabalhar novamente diversos conceitos relacionados às especificidades dessa modalidade da língua, tais como alongamentos, hesitações, truncamentos e turnos de fala.

\section{CONSIDERAÇÕES FINAIS}

Buscamos, no presente artigo, descrever e analisar o modo como uma professora do ensino fundamental de uma escola pública do Estado de Pernambuco aborda a oralidade e suas relações com a escrita em sua sala de aula e, a partir disso, destacar inovações que consideramos importantes para o contexto geral do ensino de português como língua materna.

Na prática investigada, observamos que a modalidade oral da língua é tomada como objeto de ensino e que suas relações de semelhança e diferença com a modalidade escrita são discutidas com profundidade. Acreditamos que essa não é uma característica que pode ser generalizada em relação a todos os professores de língua portuguesa, e que um dos fatores que pode ter determinado essa característica nas aulas dessa professora em particular é sua formação acadêmica inicial (na qual ela realizou pesquisas de iniciação científica) e posterior. Defendemos, portanto, a necessidade de incentivos a uma formação sólida dos professores, voltada para o ensino de gêneros textuais e com foco no trabalho com a modalidade oral e suas relações com a escrita. 
Pudemos perceber também que a abordagem das duas modalidades da língua, vistas ambas como situadas no conjunto das práticas sociais, foi realizada a partir de uma perspectiva sociointeracionista; especificamente, a oralidade foi tratada como uma modalidade da língua que possui características próprias.

Destacamos, por fim, o fato de que o ensino da oralidade foi uma oportunidade para que os alunos se colocassem por meio de suas falas, de modo a que se constituíssem efetivamente como participantes das aulas e como construtores dos próprios discursos. Dessa maneira, ficou clara a tomada da linguagem, por parte da professora, como "a mais usual forma de encontro, desencontro e confronto de posições." (GERALDI, 2010, p. 34).

\section{REFERÊNCIAS}

ANDRÉ, Marli Eliza D. A. Etnografia da prática escolar. 15 ed. Campinas: Papirus, 2008.

ANTUNES, Irandé. Aula de português: encontro e interação. São Paulo: Parábola Editorial, 2003.

BOTLER, Laís Maria A. Rosal. Gêneros orais e ensino de língua portuguesa: concepções e práticas. 2013. 210 f. Dissertação (Mestrado em Educação). Programa de Pós-Graduação em Educação, Universidade Federal de Pernambuco, Recife, 2013.

BRAUN, William Augusto Fagundes. O ensino-aprendizagem do oral e os PCN. Rev. Moara. n. 19. p. 39-43. Belém: jan.-jun., 2003.

CRESCITELLI, Mercedes Canha; REIS, Amália Salazar. O ingresso do texto oral em sala de aula. In: ELIAS, Vanda Maria (org.) Ensino da Língua Portuguesa: oralidade, escrita e leitura. São Paulo: Contexto, 2011, p. 29-40.

DOLZ, Joaquim; SCHNEUWLY, Bernard; HALLER, Sylvie. O oral como texto: como construir um objeto de ensino. In: SCHNEUWLY, Bernard; DOLZ, Joaquim. Gêneros orais e escritos na escola. Tradução e organização de Roxane Rojo e Glaís Sales Cordeiro. Campinas: Mercado das Letras, 2004, p. 125-155.

FÁVERO, Leonor Lopes; ANDRADE, Maria Lúcia C.V.O.; AQUINO, Zilda, G.O. Oralidade e escrita: perspectivas para o ensino de língua materna. São Paulo: Cortez, 1999.

. Reflexões sobre oralidade e escrita no ensino de língua portuguesa. In: ELIAS, Vanda Maria (org.) Ensino da Língua Portuguesa: oralidade, escrita e leitura. São Paulo: Contexto, 2011, p. 13-28.

GERALDI, João Wanderley. A aula como acontecimento. São Carlos: Pedro \& João Editores, 2010.

MARCUSCHI, Luiz Antônio. Da fala para a escrita: atividades de retextualização. 10.ed., São Paulo: Cortez, 2010.

. \& DIONÍSIO, Ângela Paiva. Princípios gerais para o tratamento das relações entre a fala e a escrita. In: (org.). Fala e escrita. Belo Horizonte: Autêntica, 2005, p. 13-30.

MILANEZ, Wânia. Pedagogia do oral: condições e perspectivas para sua aplicação no português. Campinas: Sama, 1993. 
SCHNEUWLY, Bernard. Palavra e ficcionalização: um caminho para o ensino da linguagem oral. In: SCHNEUWLY, Bernard; DOLZ, Joaquim. Gêneros orais e escritos na escola. Tradução e organização de Roxane Rojo e Glaís Sales Cordeiro. Campinas: Mercado das Letras, 2004, p.109-124. 